\title{
Safe and Simplified Salvage Technique for Exposed Implantable Cardiac Electronic Devices under Local Anesthesia
}

\author{
Chang Young Jung, Tae Gon Kim, Sung-Eun Kim, Kyu-Jin Chung, Jun Ho Lee, Yong-Ha Kim \\ Department of Plastic and Reconstructive Surgery, Yeungnam University College of Medicine, Daegu, Korea
}

Background Skin erosion is a dire complication of implantable cardiac pacemakers and defibrillators. Classical treatments involve removal of the entire generator and lead systems, however, these may result in fatal complications. In this study, we present our experience with a simplified salvage technique for exposed implantable cardiac electronic devices (ICEDs) without removing the implanted device, in an attempt to reduce the risks and complication rates associated with this condition.

Methods The records of 10 patients who experienced direct ICED exposure between January 2012 and December 2015 were retrospectively reviewed. The following surgical procedure was performed in all patients: removal of skin erosion and capsule, creation of a new pocket at least $1.0-1.5 \mathrm{~cm}$ inferior to its original position, migration of the ICED to the new pocket, and insertion of closed-suction drainage. Patients with gross local sepsis or septicemia were excluded from this study.

Results Seven patients had cardiac pacemakers and the other 3 had implantable cardiac defibrillators. The time from primary ICED placement to exposure ranged from 0.3 to 151 months (mean, 29 months. Postoperative follow-up in this series ranged from 8 to 31 months (mean follow-up, 22 months). Among the 10 patients, none presented with any signs of overt infection or cutaneous lesions, except 1 patient with hematoma on postoperative day 5 . The hematoma was successfully treated by surgical removal and repositioning of the closedsuction drainage.

Conclusions Based on our experience, salvage of exposed ICEDs is possible without removing the device in selected patients.

Keywords Defibrillators / Infection / Salvage therapy / Surgical flaps

\author{
Correspondence: Tae Gon Kim \\ Department of Plastic and \\ Reconstructive Surgery, Yeungnam \\ University College of Medicine, 170 \\ Hyeonchung-ro, Nam-gu, Daegu \\ 42415, Korea \\ Tel: $+82-53-620-3483$ \\ Fax: +82-53-626-0705 \\ E-mail: kimtg0919@daum.net
}

Received: 11 Jul $2016 \bullet$ Revised: 20 Oct $2016 \bullet$ Accepted: 20 0ct 2016

pISSN: 2234-6163・ elSSN: 2234-6171 • https://doi.org/10.5999/aps.2017.44.1.42 • Arch Plast Surg 2017;44:42-47

\section{INTRODUCTION}

Infection or contamination of implantable cardiac electronic device (ICEDs) due to skin erosion is difficult to treat with antibiotics alone. The classic recommendation for the treatment of infected ICEDs is complete removal of the infected ICED and reinsertion at a new site. To date, explantation of the entire device - including patches, leads, and generators - and transpositioning it to a new pocket has been considered the safest treatment method for infected ICEDs $[1,2]$. 
However, explantation of the entire device has been shown to cause serious complications, such as myocardiac tissue damage, cardiac valve injuries, subclavian vein perforation, cardiac tamponade, and even death. These complications are due to the inflammatory response and tissue ingrowth of the patches into the soft tissue, vessels, and myocardium $[3,4]$.

Numerous reports of successful treatment have been documented in which exposed ICEDs were salvaged in an attempt to reduce fatal complications. Treatment with atrioventricular (AV) lead preservation and placement of a new generator unit has been considered [5]. The use of only local debridement and closed irrigation systems with antibiotics has been associated with superior long-term results [6,7]. Additionally, other options, including the use of a closed irrigation system when relocating the pacemaker under the pectoralis major muscle, have also been documented [6].

Although these methods have shown good results, they are still associated with tissue or vessel damage, and the procedures were performed under general anesthesia.

In this study, we introduce our experience with a simplified salvage technique for exposed ICEDs performed under local anesthesia. In this technique, the device is not removed, in an attempt to reduce the risks and complication rates associated with exposed ICEDs.

\section{METHODS}

This study was performed as a retrospective review of 10 patients treated for locally infected or extruded ICEDs over a period of 48 months, from January 2012 to December 2015 (Fig. 1). The inclusion criterion was the presence of only local symptoms at the exposed ICED site. In all cases, microbiological cul-

\section{Fig. 1. A case of defibrillator exposure}

A defibrillator was exposed with mild capsular contracture and skin erosion 1.6 years after insertion. An erythematous skin lesion with mild tenderness around the wound was also noted.

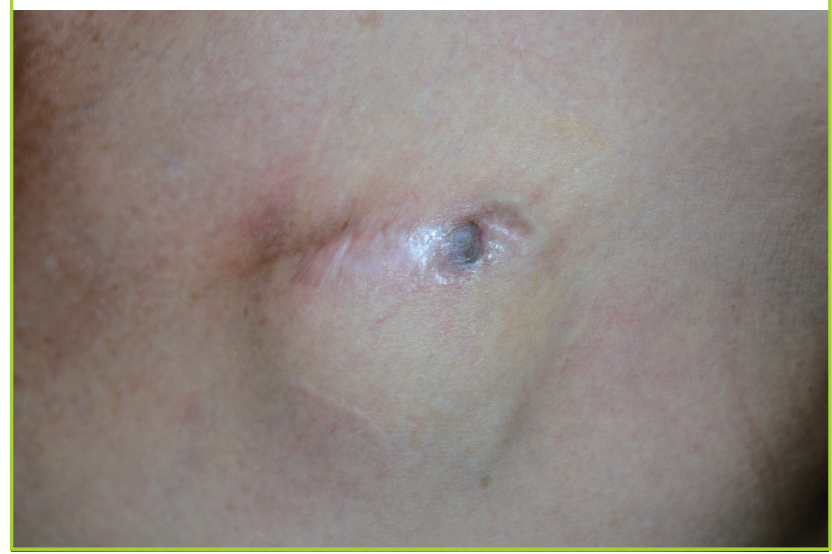

tures were taken from the wound, and parenteral antibiotics, to which the organisms were sensitive, were started immediately postoperatively and were continued for 14 days. Patients with a diagnosis of systemic sepsis or septicemia, septic shock, or overt infective endocarditis, or with a history of vegetation on echocardiography or infective endocarditis, were excluded from this study.

\section{Surgical procedure}

Under local anesthesia, a preoperative design was made at least $1.0-1.5 \mathrm{~cm}$ inferior to its original position (Fig. 2). Povidone-iodine skin preparation was carried out. The skin surrounding the site of the generator exposure was excised, extending to allow the temporary removal of the generator device and leads. All thinned skin surrounding the exposure site was also excised along with the primary excision. Careful temporary removal of the generator device from the pocket without disconnection of the leads was performed, followed by gently untwisting the unburied part of the leads (Fig. 3). A swab culture from the pocket was obtained intraoperatively.

A total capsulectomy was then performed. With a combination of Metzenbaum scissors, electrocautery, and a No. 11 blade, the entire periprosthetic fibrous capsule that had been in intimate contact with the implanted generator device was completely removed. Furthermore, the capsule surrounding the lead

\section{Fig. 2. Preoperative design around the exposed ICED}

The preoperative design was made at least $1.0-1.5 \mathrm{~cm}$ inferior to its original position, including the unhealthy, thinned skin to be excised. ICED, implantable cardiac electronic device.

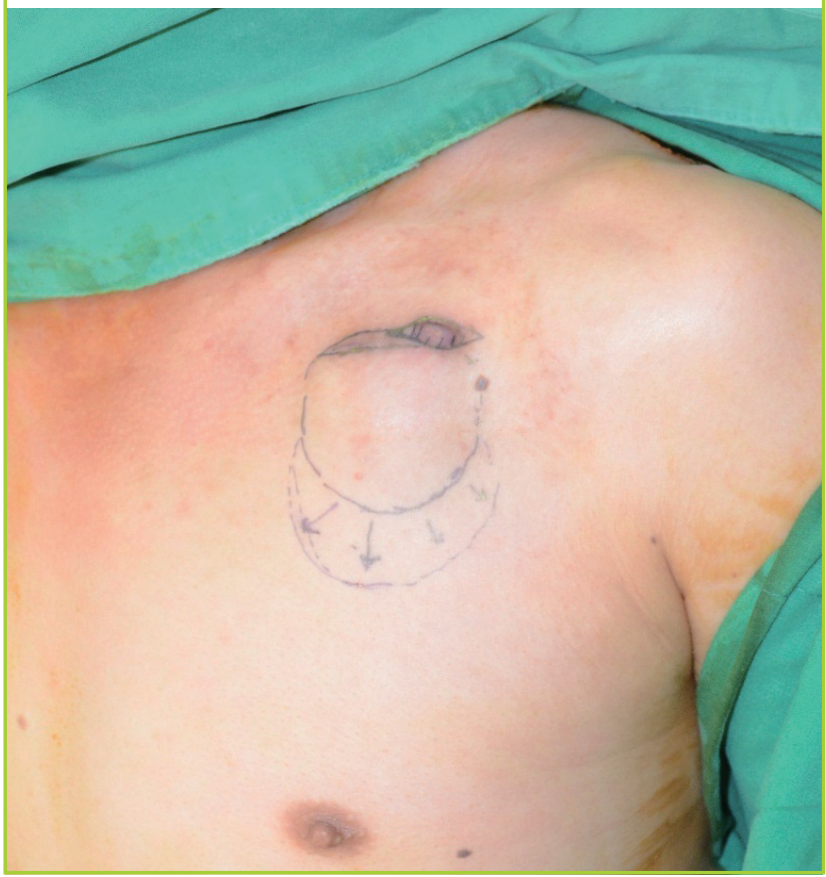


Fig. 3. Temporary generator removal without lead disconnection

Careful temporary removal of the generator device from the pocket was performed, followed by gently untwisting the unburied part of the leads. After untwisting the unburied part of the leads, careful dissection and debridement of the entire fibrous capsule and all unhealthy granulation tissue surrounding the ICED were performed with Metzenbaum scissors. ICED, implantable cardiac electronic device.

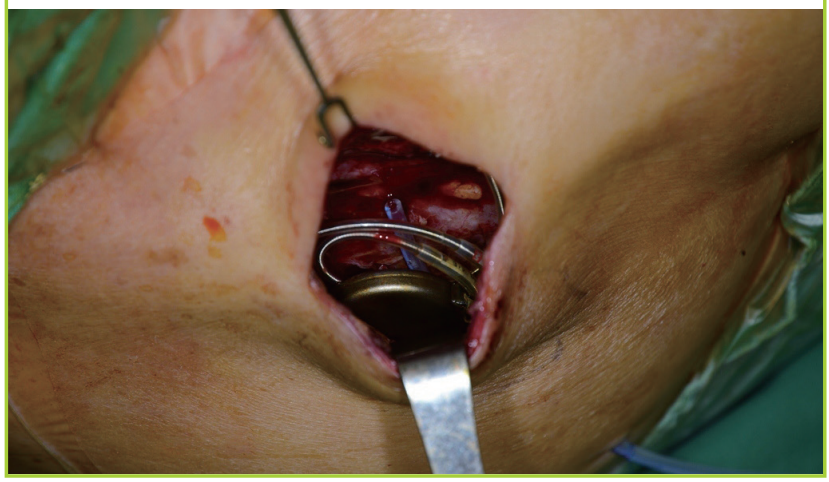

system was removed to its most proximal point in the region immediately preceding the entry of the leads into the subclavian vein. All purulent materials were then copiously irrigated from the wound with povidone-iodine solution and wrapped within sterile povidone-iodine-soaked gauze. The generator device and the leads were scrubbed with povidone-iodine solution (Fig. 4). Pocket irrigation was carried out with an antibiotic solution (cephazolin, gentamicin, and bacitracin).

To create a new pocket, careful dissection was performed to the level of the prepectoral fascia from the inferior aspect of the preexisting pocket, maintaining the previous layer with bipolar electrocautery. If necessary, gentle manual dissection was also performed. At this time, in order to advance the generator to the new pocket, the lead was carefully released with Metzenbaum scissors from the surrounding granular tissue on the posterior surface of the previous pocket.

The generator was then placed into the new pocket. After confirming that the generator and leads were properly replaced, the devices were thoroughly irrigated with povidone-iodine solution. Hemostasis was obtained using electrocautery. Careful examination was taken to secure that the leads were smoothly placed around the generator without kinking or twisting. The subcutaneous layer was closed without tension, using interrupted Vicryl 4-0 sutures. The drains were sutured securely to the skin, which was closed with nylon 5-0 sutures. Closed-suction drainage was inserted, and the leads were repositioned to minimize skin irritation. The soft tissues were closed layer by layer after moderate dissection to minimize tension (Fig. 5). Compressive dressing was done to reduce skin tension and hematoma formation.

\section{Fig. 4. Management before replacing the ICED}

After exposure of the device and the leads, scrubbing and irrigation with povidone-iodine were performed. ICED, implantable cardiac electronic device.

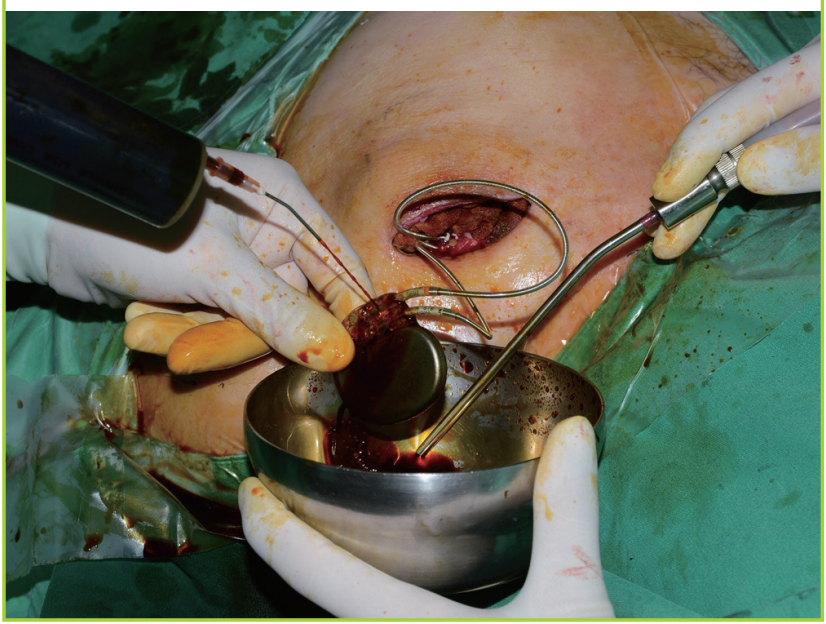

\section{Fig. 5. Drainage insertion and wound closure \\ Soft tissues were closed layer by layer after moderate dissection, mini- mizing the tension with closed-suction drainage insertion.}

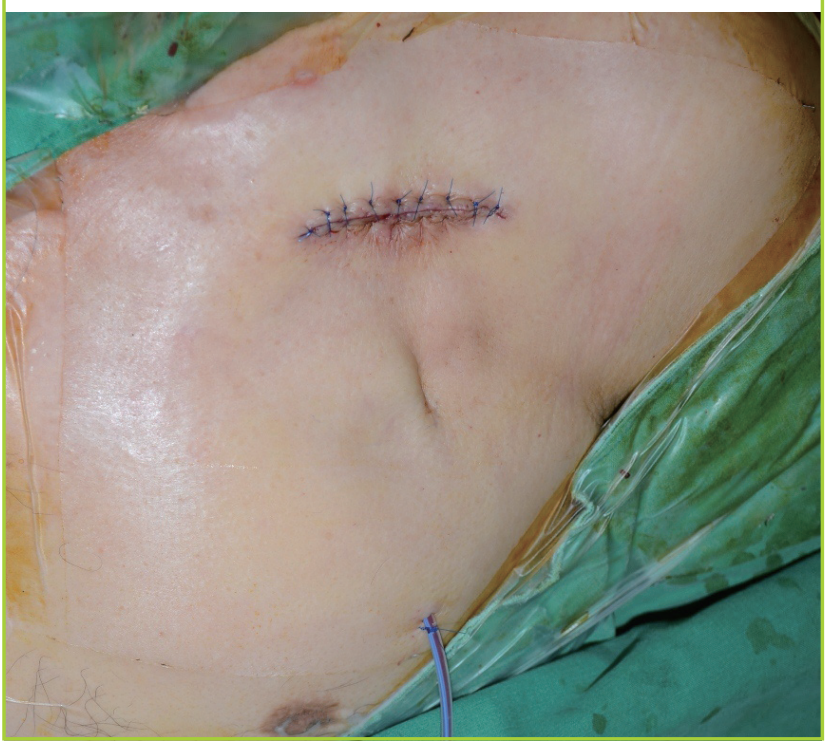

\section{RESULTS}

Seven patients had cardiac pacemakers, while the other 3 had implantable cardiac defibrillators. Six patients were male and 4 were female, and their age ranged from 39 to 78 years (mean age, 60 years). The time from primary ICED placement to exposure ranged from 0.3 to 151 months (mean, 29 months). Maintenance of drainage ranged from 4 to 10 days (mean, 6.6 days), and postoperative follow-up in this series ranged from 8 to 31 months (mean follow-up, 22 months). All patients had 
Table 1. Characteristics of patients

\begin{tabular}{|c|c|c|c|c|c|c|c|}
\hline Case no. & Sex & Age (yr) & $\begin{array}{c}\text { Duration of } \\
\text { implantation (mo) }\end{array}$ & $\begin{array}{l}\text { Existing device } \\
\text { type }\end{array}$ & $\begin{array}{l}\text { Result of intraoperative } \\
\text { swap culture }\end{array}$ & $\begin{array}{c}\text { Duration of } \\
\text { drainage (day) }\end{array}$ & $\begin{array}{c}\text { Follow-up period } \\
\text { (mo) }\end{array}$ \\
\hline 1 & Male & 39 & 0.3 & Pacemaker & None & 4 & 8 \\
\hline 2 & Male & 78 & 151 & Pacemaker & None & 10 & 31 \\
\hline 3 & Female & 59 & 26 & Pacemaker & None & 8 & 32 \\
\hline 4 & Male & 62 & 20 & Defibrillator & MRSA & 8 & 24 \\
\hline 5 & Male & 63 & 8 & Pacemaker & None & 7 & 30 \\
\hline 6 & Female & 57 & 11 & Pacemaker & MRSA & 9 & 12 \\
\hline 7 & Female & 69 & 15 & Defibrillator & None & 5 & 22 \\
\hline 8 & Female & 47 & 20 & Pacemaker & None & 5 & 21 \\
\hline 9 & Male & 65 & 20 & Pacemaker & None & 5 & 20 \\
\hline 10 & Male & 61 & 19 & Defibrillator & None & 5 & 20 \\
\hline
\end{tabular}

negative wound cultures, except for 2 patients who had methicillin-resistant Staphylococcus aureus (Table 1). Five patients received intravenous first-generation cephalosporin for 14 days, 3 patients received third-generation cephalosporin for 14 days, and 2 patients received vancomycin perioperatively and for 14 days postoperatively.

Among the 10 patients, none showed any postoperative signs of overt infection or cutaneous lesions, including granulomatous scar abnormalities. However, 1 patient developed a hematoma on postoperative day 5 . The hematoma was successfully treated by surgical removal and repositioning of the closed-suction drainage. None of the patients developed any signs of implant exposure or impending rupture. None required surgical explantation of the system.

\section{DISCUSSION}

Infection, erosion, and exposure of ICEDs are severe complications. Traditional surgical treatments of infected and exposed ICEDs have involved the explantation of the entire system, including the generator, all leads, and patches, followed by the replacement of a new device system to a new noninfected site [8]. Although this method has been proven to result in the complete resolution of infected ICEDs, major complications, including superior vena cava perforation, right ventricular perforation, cardiac valvular injury, cardiac tamponade, and sudden death, have been well documented during explantation, with complication rates ranging from $2.4 \%$ to $17 \%[3,9,10]$.

For this reason, salvage of an infected or exposed ICED often becomes necessary. In 1995, Foster [11] reported successful subpectoral replacement with a lateral axillary approach. Jensen [12] reported a case of subpectoral implantable generator relocation from an abdominal pocket using an axillary tunneling technique. In 2010, Al-Bataineh et al. [13] reported a lateral ax- illary approach to the subpectoral plane in patients with ipsilateral prepectoral infection and limited venous access. No recurrence of infection was observed, with only 1 hematoma and 1 pneumothorax in the 16 patients who were treated. More recently, in 2012, Knepp et al. [14] described repositioning devices under the pectoralis muscle using an anterior muscle-splitting approach under intravenous sedation with local anesthesia.

Although many authors have described success with ICED replacements using subpectoral placement, a considerable number of patients who have previously undergone ICED insertion tend to be reluctant to undergo general anesthesia, and suffer from pain at the moment of subpectoral dissection or muscle-splitting even under local anesthesia with a long-lasting operation.

Therefore, to solve these problems, the author struggled to find a simpler way to salvage the entire ICED under local anesthesia. Meanwhile, the primary placement of cardiac devices in the subcutaneous versus subpectoral space was compared [15]. No significant differences in complication rates were found. The placement of devices into the subcutaneous space, currently adopted by most electrophysiology laboratories, allows a shorter procedural time and requires less demanding technical maneuvers.

Conservative management is not a novel concept. Efforts have been made to reduce the potential risks associated with explantation and new replacement of all devices. Taylor et al. [16] described the treatment of infected pacemakers with revision and placement of a continuous irrigation system. Hurst et al. [6] described similar treatments, with the use of closed antibiotic irrigation for lead preservation. Lee et al. [17] described the treatment of infected device pockets with revision followed by the placement of a continuous irrigation system and closed antibiotic irrigation, with successful outcomes. However, these approaches do not move the device into a sterile tissue plane, meaning that the long-term sterility after discontinuation of the antibiotic irrigation systems is questionable. 
Table 2. Summary of studies

\begin{tabular}{|c|c|c|c|c|c|c|c|}
\hline $\begin{array}{l}\text { Relocation } \\
\text { layer }\end{array}$ & Study & No. of cases & Anesthesia & ICED management & Characteristics & $\begin{array}{l}\text { Follow-up } \\
\text { (mo) }\end{array}$ & Complication \\
\hline \multirow[t]{3}{*}{ Prepectoral } & $\begin{array}{l}\text { Yamada et al. [18], } \\
2002\end{array}$ & 18 & $\begin{array}{l}\text { Local anesthesia before } \\
\text { 1995, General } \\
\text { anesthesia after } 1995\end{array}$ & $\begin{array}{l}\text { New generator } \\
\text { implantation but AV } \\
\text { leads preservation }\end{array}$ & $\begin{array}{l}\text { Subclavian incision for } \\
\text { leads management }\end{array}$ & 58 & Reinfection $(n=1)$ \\
\hline & $\begin{array}{l}\text { Griffith et al. [20], } \\
1994\end{array}$ & 38 & General anesthesia & Lead preservation & $\begin{array}{l}\text { Creation of a new } \\
\text { ipsilateral } \\
\text { subcutaneous pocket }\end{array}$ & 21.3 & Reinfection $(n=7)$ \\
\hline & $\begin{array}{l}\text { Kolker et al. [5], } \\
2007\end{array}$ & 6 & General anesthesia & $\begin{array}{l}\text { New generator } \\
\text { implantation but AV } \\
\text { leads preservation }\end{array}$ & $\begin{array}{l}\text { Local rhomboid skin } \\
\text { flap coverage }\end{array}$ & 22 & Hematoma $(n=1)$ \\
\hline \multirow[t]{5}{*}{ Subpectoral } & $\begin{array}{l}\text { Hurst et al. [6], } \\
1986\end{array}$ & 19 & Unspecified & $\begin{array}{l}\text { Temporary removal of } \\
\text { generator from pocket } \\
\text { but pacing }\end{array}$ & Closed irrigation system & 24 & Reinfection $(n=1)$ \\
\hline & Foster [11], 1995 & 6 & Unspecified & $\begin{array}{l}\text { Temporary removal of } \\
\text { generator from pocket } \\
\text { but pacing }\end{array}$ & $\begin{array}{l}\text { Lateral axillary } \\
\text { approach }\end{array}$ & 6.5 & None \\
\hline & Jensen [12], 1998 & 1 & General anesthesia & New generator implatation & $\begin{array}{l}\text { Reposition of the } \\
\text { generator from an } \\
\text { abdominal to a } \\
\text { subpectoral pocket }\end{array}$ & 6 & None \\
\hline & $\begin{array}{l}\text { Al-Bataineh et al. } \\
\text { [13], } 2010\end{array}$ & 16 & $\begin{array}{l}\text { IV sedation with local } \\
\text { anesthesia }\end{array}$ & $\begin{array}{c}\text { New generator } \\
\text { implantation }\end{array}$ & $\begin{array}{l}\text { Lateral axillary } \\
\text { approach }\end{array}$ & From 3 to 24 & $\begin{array}{l}\text { Hematoma }(n=1), \\
\text { pneumothorax }(n=1)\end{array}$ \\
\hline & $\begin{array}{l}\text { Knepp et al. [14] } \\
2012\end{array}$ & 7 & $\begin{array}{l}\text { IV sedation with local } \\
\text { anesthesia }\end{array}$ & $\begin{array}{c}\text { New generator } \\
\text { implantation }\end{array}$ & Anterior muscle splitting & 21 & Wire exposure $(n=1)$ \\
\hline
\end{tabular}

Kolker et al. [5] presented an $83 \%$ successful salvage rate with debridement, capsulectomy, and local rhomboid skin flap coverage. This procedure involved the placement of a generator with preservation of the AV leads, but carried the risk of additional donor site morbidity due to adjacent tissue being harvested and rotated into the primary defect. In our series, we performed debridement and meticulous capsulectomy of unviable infected tissue not only surrounding the generator and the leads, but also surrounding the entry into the subclavian vein as much as possible. Therefore, we were able to achieve a high success rate with salvage of both the generator and the AV leads. Yamada et al. [18] presented the successful salvage of AV lead systems in 17 of 18 patients, using surgical lead-preserving procedures to place a new generator with a new incision made just below the ipsilateral clavicle. This procedure still had the risks involved in placement of a new generator. Baddour et al. [19] have suggested an algorithm for treating patients with infected exposed ICEDs who have negative blood cultures with the removal of the entire device.

A success rate of $74 \%$ with pocket debridement, lead preservation, and creation of a new ipsilateral subcutaneous pocket in patients with negative wound cultures was noted by Griffith et al. [20]. However, these strategies were confined to patients with negative wound cultures, and replacement was performed under general anesthesia. Har-Shai et al. [21] reported a sub- capsular relocation technique for the generator and lead systems. While this may be an effective salvage method, the potential of infection with the remnant capsule still exists, meaning that long-term sterility is not guaranteed (Table 2).

In our series, we successfully treated $90 \%$ of our patients ( 9 of 10) with local infection, skin erosion, or exposure of an ICED under local anesthesia. The technique that we propose involves the complete removal of the preexisting capsule, theoretically decreasing the nidus for persistent infection. The pocket change reintroduces the indwelling lead system and a generator device to a pristine and well-vascularized pocket. Closed-suction drainage minimizes the potential for periprosthetic fluid or blood collection. Among the 10 patients, only 1 patient developed hematoma in the early postoperative period, which was successfully treated by surgical removal of the hematoma and repositioning of the closed-suction drainage.

The basis for this approach is the determination that the infection is localized and confined to the ICED pocket. It should be reiterated that no patient in the current series had signs suggestive of systemic infection; none were febrile, none had leukocytosis, and no positive blood cultures were found.

If severe infectious conditions such as endocarditis are suspected in such patients, transesophageal echocardiography is recommended for a valvular evaluation prior to any lead-sparing procedures [19]. Furthermore, we believe that complete explan- 
tation of the entire ICED is required if fulminant mediastinitis is evident, either clinically or radiographically $[2,17,22,23]$.

On the basis of our experience, we conclude that salvaging exposed ICEDs is possible without removing the devices in selected patients under local anesthesia. Furthermore, this may be an alternative method leading to less morbidity than the removal of the entire device. However, the decision to proceed with this simplified method must be predicated upon proof that no systemic infection is present.

\section{ORCID}

Tae Gon Kim http://orcid.org/0000-0002-6738-4630

Kyu-Jin Chung http://orcid.org/0000-0001-6335-1818

Jun Ho Lee http://orcid.org/0000-0002-0062-6420

Yong-Ha Kim http://orcid.org/0000-0002-1804-9086

\section{REFERENCES}

1. Geha AS, Elefteriades JA, Hsu J, et al. Strategies in the surgical treatment of malignant ventricular arrhythmias: an 8-year experience. Ann Surg 1992;216:309-16.

2. Kelly PA, Wallace S, Tucker B, et al. Postoperative infection with the automatic implantable cardioverter defibrillator: clinical presentation and use of the gallium scan in diagnosis. Pacing Clin Electrophysiol 1988;11:1220-5.

3. Vogt PR, Sagdic K, Lachat M, et al. Surgical management of infected permanent transvenous pacemaker systems: ten year experience. J Card Surg 1996;11:180-6.

4. Wilhelm MJ, Schmid C, Hammel D, et al. Cardiac pacemaker infection: surgical management with and without extracorporeal circulation. Ann Thorac Surg 1997;64:1707-12.

5. Kolker AR, Redstone JS, Tutela JP. Salvage of exposed implantable cardiac electrical devices and lead systems with pocket change and local flap coverage. Ann Plast Surg 2007; 59:26-9.

6. Hurst LN, Evans HB, Windle B, et al. The salvage of infected cardiac pacemaker pockets using a closed irrigation system. Pacing Clin Electrophysiol 1986;9:785-92.

7. Furman RW, Hiller AJ, Playforth RH, et al. Infected permanent cardiac pacemaker. Management without removal. Ann Thorac Surg 1972;14:54-8.

8. Furman S. Implantable cardioverter defibrillator infection. Pacing Clin Electrophysiol 1990;13:1351.

9. Brodman R, Frame R, Andrews C, et al. Removal of infected transvenous leads requiring cardiopulmonary bypass or inflow occlusion. J Thorac Cardiovasc Surg 1992;103:649-54. 10. Byrd CL. Advances in device lead extraction. Curr Cardiol
Rep 2001;3:324.

11. Foster AH. Technique for implantation of cardioverter defibrillators in the subpectoral position. Ann Thorac Surg 1995;59:764-7.

12. Jensen SM. Reposition of an implantable cardioverter defibrillator generator from an abdominal pocket to a subpectoral location using the existing electrode. Pacing Clin Electrophysiol 1998;21:627-8.

13. Al-Bataineh M, Sajadi S, Fontaine JM, et al. Axillary subpectoral approach for pacemaker or defibrillator implantation in patients with ipsilateral prepectoral infection and limited venous access. J Interv Card Electrophysiol 2010;27:137-42.

14. Knepp EK, Chopra K, Zahiri HR, et al. An effective technique for salvage of cardiac-related devices. Eplasty 2012; 12:e8.

15. Gold MR, Peters RW, Johnson JW, et al. Complications associated with pectoral cardioverter-defibrillator implantation: comparison of subcutaneous and submuscular approaches. Worldwide Jewel Investigators. J Am Coll Cardiol 1996;28:1278-82.

16. Taylor RL, Cohen DJ, Widman LE, et al. Infection of an implantable cardioverter defibrillator: management without removal of the device in selected cases. Pacing Clin Electrophysiol 1990;13:1352-5.

17. Lee JH, Geha AS, Rattehalli NM, et al. Salvage of infected ICDs: management without removal. Pacing Clin Electrophysiol 1996; 19:437-42.

18. Yamada M, Takeuchi S, Shiojiri Y, et al. Surgical lead-preserving procedures for pacemaker pocket infection. Ann Thorac Surg 2002;74:1494-9.

19. Baddour LM, Cha YM, Wilson WR. Clinical practice: infections of cardiovascular implantable electronic devices. $\mathrm{N}$ Engl J Med 2012;367:842-9.

20. Griffith MJ, Mounsey JP, Bexton RS, et al. Mechanical, but not infective, pacemaker erosion may be successfully managed by re-implantation of pacemakers. Br Heart J 1994;71: 202-5.

21. Har-Shai Y, Amikam S, Ramon Y, et al. The management of exposed cardiac pacemaker pulse generator and electrode using restricted local surgical interventions; subcapsular relocation and vertical-to-horizontal bow transposition techniques. Br J Plast Surg 1990;43:307-11.

22. Gerzof SG, Oates ME. Imaging techniques for infections in the surgical patient. Surg Clin North Am 1988;68:147-65.

23. Almassi GH, Olinger GN, Troup PJ, et al. Delayed infection of the automatic implantable cardioverter-defibrillator: current recognition and management. J Thorac Cardiovasc Surg 1988;95:908-11. 